\title{
Review of: "Sperm exposure to accessory gland secretions alters the transcriptomic response of the endometrium in cattle"
}

\author{
Rosanna Serafini
}

Potential competing interests: The author(s) declared that no potential competing interests exist.

Manuscript title: Sperm exposure to accessory gland secretions alters the transcriptomic response of the endometrium in cattle

Dear Editor,

The authors presented a detailed study on endometrial gene expressions in explants from slaughtered cows exposed to epididymal, ejaculated sperm or epididymal exposed or not to seminal plasma. This is a very interesting topic, as the effect of seminal plasma on endometrial response is not well understood. The experimental design proposed is robust and the manuscript is well written, and it drives the readers to the objectives of the study. Some clarifications in materials and methods are needed. I would accept this manuscript with minor revisions.

Few questions should be addressed:

1. Authors state that "factors of AG origin modulate the interaction between sperm and the endometrium in cattle". In other species, such as in the mare, inflammation of the uterus after breeding can be considered as a normal response. However, susceptible mares have an excess of fluid accumulation, formed by inflammatory cells, semen and uterine secretions. Gene expression studies have shown that these mares have an increase in cytokine signaling pathway (TNFa, IL and SAA) following infusion with bacteria or sperm (Christoffersen M, Woodward E, Bojesen AM, et al. Inflammatory responses to induced infectious endometritis in mares resistant or susceptible to persistent endometritis. BMC Vet Res.

2012;8:41; Fumuso E, Aguilar J, Giguere S, et al. Interleukin-8 (IL-8) and 10 (IL-10) mRNA transcriptions in the endometrium of normal mares and mares susceptible to persistent post-breeding endometritis. Anim Reprod Sci. 2006;94:282-285). Do authors consider that the "female factor" could be a potential reason in the different genes found following exposure to epidydimal or ejaculated sperm?

2. Are the bulls used in this study bulls with proven fertility? How many ejaculates were used from each bull? As regarding epididymal sperm, authors used $1 \mathrm{~mL}$ of seminal plasma with how much volume of sperm. What's the \% SP sperm were exposed to? Please add this information in the materials and methods. 
3. Other studies demonstrated that the effect of seminal plasma can be detrimental for sperm undergoing storage and showed that seminal plasma should be mostly removed by centrifugation to preserve sperm membrane integrity, DNA quality and motility over time (Varner DD, Blanchard TL, Love CC, Garcia MC, Kenney RM. Effects of semen fractionation and dilution ratio on equine spermatozoal motility parameters. Theriogenology 1987;28:709-23; Brinsko SP, Crockett EC, Squires EL. Effect of centrifugation and partial removal of seminal plasma on equine spermatozoal motility after cooling and storage. Theriogenology 2000;54:129-36). Authors in this study used a density gradient, probably selecting the best sperm. Authors did not show any sperm analysis (motility, morphology, viability) in this study. Is it possible to integrate the materials and methods with any sperm measure? It would have been interesting to have groups of bulls with different fertility to compare the effects on gene expression.

4. Authors conclude saying that the impact of the endometrial regulation driven by sperm and AG factors on cattle fertility remains to be elucidated. Have authors considered to conduct in vivo studies to elucidate these findings?

5. Fig.2 can authors define what is green, red and black to make easier for readers to understand. 